American Journal of Applied Sciences 5 (10): 1392-1396, 2008

ISSN 1546-9239

(C) 2008 Science Publications

\title{
Transforming Spatio-Temporal Yield Maps to Classified Management Zone Maps for Efficient Management of Oil Palm
}

\author{
${ }^{1}$ Abdul Rahim Anuar, ${ }^{2}$ Kah Joh Goh, ${ }^{2}$ Tee Bee Heoh and ${ }^{3}$ Osumanu Haruna Ahmed \\ ${ }^{1}$ Department of Land Management, Faculty of Agriculture, Universiti Putra Malaysia, \\ 43400 Serdang, Selangor, Malaysia \\ ${ }^{2}$ Applied Agricultural Research Sdn. Bhd., Locked Bag 212, Sungai Buloh Pos Office, \\ 47000 Sungai Buloh, Selangor, Malaysia \\ ${ }^{3}$ Department of Crop Science, Faculty of Agriculture and Food Sciences, Universiti Putra Malaysia \\ Bintulu Campus, 97008 Bintulu, Sarawak, Malaysia
}

\begin{abstract}
One of the major challenges in oil palm plantations today is proper interpretation of yield maps for site-specific management and development of classified management zone maps for its efficient management. A study was conducted on an on-going fertilizer response trial in Sabah, Malaysia to examine the possibility of converting spatio-temporal yield maps of oil palm to classified management zone maps for practical management purposes. Two clusters of palms were selected for the study; with and without $\mathrm{N}$ fertilizer applications for the past 10 years. Fresh fruit bunch (ffb) yields were summarized on an annual basis. Point kriging method of geostatistics was used to interpolate ffb yields at unsampled locations. A classified management zone map was developed based on the spatial and temporal stability yield maps from 1992-1999. Nine management zones were derived form the spatio-temporal features in the ffb yield variations for decision making. Two management zones of high, stable yields and high, fairly stable yields and 4 management zones of moderate, stable yields; moderate, fairly stable yields; moderate, unstable yields; and low, unstable yields were then demarcated from area with and without $\mathrm{N}$ applications for practical management purposes. The results demonstrate the potential of transforming spatial and temporal stability of ffb yield maps from multiyear yield data to practical classified management zone maps for site-specific oil palm management particularly for fertilizer application. However, the potential of misinterpretation of yield maps can be high if limited data are available. Further work is necessary to ascertain the minimum number of palms and years required for the generation of meaningful yield maps and management zones.
\end{abstract}

Key words: Temporal variability, spatial variability, nitrogen fertilizer, oil palm yield, Malaysia, oil palm yield management maps

\section{INTRODUCTION}

The ffb yields of oil palm are harvested over extended periods during the cropping cycle. This crop is known to exhibit high spatial and temporal yield variation $^{[1,2,3]}$ and biennial or triennial yield cycle ${ }^{[3,4]}$. The high spatial and temporal yield variation of $\mathrm{ffb}$ is probably best represented with multiple-year yield maps for better visualization. Building multiple-year yield database is needed to detect its seasonal and annual fluctuations ${ }^{[5]}$ in order to manage them efficiently. This technique is now commonly used in developed countries to interpret and manage the yield variations of many crops for precision farming ${ }^{[6]}$.

Also, it could be used to classify a large field into different management zones for site specific inputs to optimize productivity and profitability; two of the most important keys towards sustainability of oil palm plantations ${ }^{[7]}$. Management zoning is widely practised in the oil palm plantations but its spatial scale at 30 to 60 ha is generally too large for site-specific management ${ }^{[8,9]}$. Goh et al.$^{[3]}$ demonstrated the need for developing a method to combine multiple-year yield database for oil palm in order to accurately define its

Corresponding Author: Osumanu Haruna Ahmed, Department of Land Management, Faculty of Agriculture and Food Sciences, Universiti Putra Malaysia Bintulu Campus, Malaysia, 97008 Bintulu, Sarawak, Malaysia Tel: +6086-855406, Fax: +6086-85415 
spatial and temporal variabilities and avoid the pitfall in the interpretation of multiple-year yield maps ${ }^{[6,9]}$.

However, the interpretation of trend from multiple yield maps of the same location and the development of a method to optimize management zoning for efficient management have not been well explored in the oil palm plantations. Thus, the objectives of the study were: 1. To assess the spatial and temporal yield variations of $\mathrm{ffb}$ as influenced by $\mathrm{N}$ fertilizer management and 2. To convert spatio-temporal yield maps of oil palm to classified management zone maps for practical management purposes.

\section{MATERIALS AND METHODS}

The experiment is located within an on-going fertilizer response trial conducted by Applied Agricultural Research Sdn. Bhd. at Sri Kunak Estate, Tawau, Sabah, Malaysia. The details of the experiment site is given by Goh et al. ${ }^{[3]}$ Two clusters of palms were selected. The first cluster composed of oil palms that had been fertilized with $\mathrm{N}$ since the treatment was first applied in 1992. Another cluster consisted of oil palms that had not been fertilized with $\mathrm{N}$ for the past 10 years. A total of 8 plots (12 palms per plot) were selected, 4 plots with $\mathrm{N}$ and 4 plots without $\mathrm{N}$ respectively. Point map of the individual palms for both treatments, which showed their relative positions in the field, was geocoded using non-earth system in meter unit. The plot size for the $\mathrm{N}$ treatment was $160 \times 90 \mathrm{~m}$ and for non-N treatment was $120 \times 115 \mathrm{~m}$ as shown in Fig. 1 . Each treatment had 48 measurement palms.

Fresh fruit bunch (ffb) yields were summarized on an annual basis. They were then adjusted using the difference method ${ }^{[10]}$ in order to remove both $\mathrm{P}$ and $\mathrm{K}$ effects. Interpolation of $\mathrm{ffb}$ yields at unsampled area was carried out by kriging ${ }^{[1]]}$ using GS+ ${ }^{\mathrm{TM}}$, Gamma Design Software (Version 3.1). The spatial yield maps of ffb were constructed by first using the point kriging method to estimate ffb yields at unsampled locations and then clustering them into ffb yield class of $5 \mathrm{t} \mathrm{ha}^{-1}$ $\mathrm{yr}^{-1}$ at equal contour intervals. To avoid irregular field shape boundary and for comparison among plots with and without $\mathrm{N}$, a rectangular field boundary was selected with extrapolated size of $165 \mathrm{~m}$ wide and 120 $\mathrm{m}$ long. The trend and stability of the yield maps were quantified by working out the corresponding mean and $\mathrm{CV}$ at each point of sampling over the past 8 years (1992-1999) as described by Blackmore ${ }^{[9]}$. Both maps

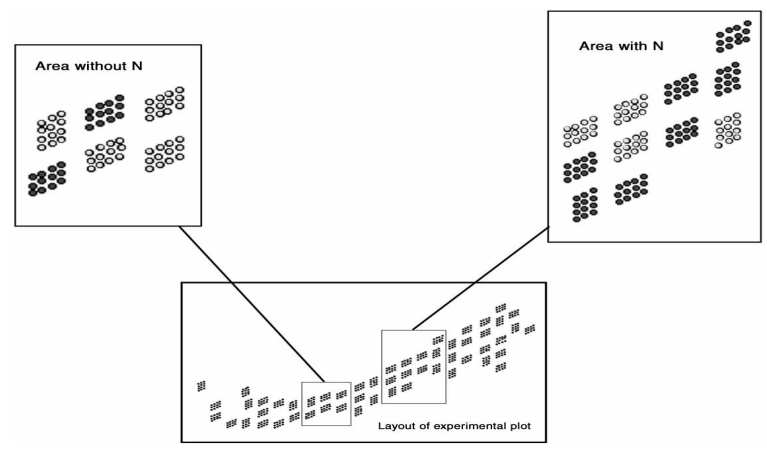

Fig. 1: Diagrammatic representation of experimental site

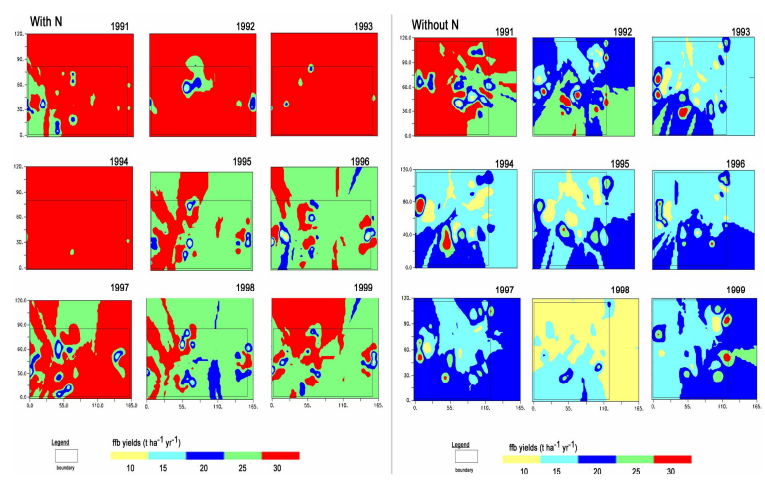

Fig. 2: Maps of $\mathrm{ffb}$ yields of oil palm for with and without $\mathrm{N}$ applications

were then combined into a classified management map with 9 different conditions of 3 yield classes and 3 temporal stability classes.

\section{RESULTS AND DISCUSSION}

Spatial annual yield maps of oil palm: The spatial yield variation of oil palm was investigated by extrapolating $\mathrm{ffb}$ yields at unsampled locations using the spherical model of point kriging. Figure 2 shows that the removal of fertilizer resulted in a significant drop in ffb yields after 1992. A large proportion of the field without $\mathrm{N}$ had ffb yields lower than $15 \mathrm{t} \mathrm{ha}^{-1} \mathrm{yr}^{-1}$ particularly in the northern part. Fresh fruit bunch yields also declined to less than $30 \mathrm{t} \mathrm{ha}^{-1} \mathrm{yr}^{-1}$ in $\mathrm{N}$ treated plots after 1994. Apart from climatic effect and yield trend, the decline in ffb yields was associated with the severe leaf damage by Darna trima, which was reported in the trial in 1994. Comparing the yield maps of areas with and without $\mathrm{N}$ applications indicated that the applications of $\mathrm{N}$ tend to sustain high $\mathrm{ffb}$ yields above $30 \mathrm{t} \mathrm{ha}^{-1} \mathrm{yr}^{-1}$. Nitrogen is probably the major factor affecting the ffb yield variation of oil palms in the experiment as obtained by Goh et al. ${ }^{[3]}$. 
Am. J. Applied Sci., 5 (10): 1392-1396, 2008

Table 1: Distribution of palms (\%) in different categories of mean and temporal yield stability as influenced by $\mathrm{N}$ treatment

\begin{tabular}{|c|c|c|c|c|c|}
\hline \multirow[b]{2}{*}{$\left(\mathrm{t} \mathrm{ha}^{-1} \mathrm{yr}^{-1}\right)$} & \multirow{2}{*}{$\begin{array}{l}\text { Temporal } \\
\text { CV }(\%)\end{array}$} & \multicolumn{2}{|c|}{ FFB yields } & \multirow[b]{2}{*}{$\geq 45$} & \multirow[b]{2}{*}{ Total } \\
\hline & & $\leq 35$ & $35<\mathrm{CV}<45$ & & \\
\hline \multirow[t]{4}{*}{ With N } & $\geq 30$ & 21.8 & 74.1 & 3.5 & 99.4 \\
\hline & $20<y<30$ & 0.6 & & & \\
\hline & $\mathrm{Y} \leq 20$ & & & & 0.6 \\
\hline & Total & 22.4 & 74.1 & 3.5 & \\
\hline \multirow[t]{4}{*}{ Without N } & $\geq 30$ & & 16.0 & 5.9 & 21.9 \\
\hline & $20<y<30$ & & 24.3 & 30.2 & 54.4 \\
\hline & $\mathrm{Y} \leq 20$ & & 10.1 & 13.6 & 23.7 \\
\hline & Total & & 50.3 & 49.7 & 100.0 \\
\hline
\end{tabular}

The multi-year yield maps also showed distinct changes in the pattern of ffb yields from the same site. For example, in both treatments, high ffb yields were noted in 1997 followed by low yields in 1998. Similarly, high yielding area in one year might become low yielding in the next without any changes in the treatments. Such temporal yield variations are common in perennial $\mathrm{crops}^{[4]}$ which increase the uncertainty in the interpretation of yield maps for site-specific crop management particularly for the following year(s).

Spatial and temporal stability yield maps of FFB: Blackmore $^{[9]}$ suggested the incorporation of trend and temporal stability of ffb yields into the yield maps to overcome the problems of their interpretation. He divided the field into management zones based on the combination of discrete classifications of mean annual yield and temporal $\mathrm{CV}$ at each sampling point over the years of study. The management zone at each sampled point was then used to produce the management zone map by kriging for future decision making.

Following Blackmore ${ }^{[9]}$, the mean annual ffb yield and temporal $\mathrm{CV}$ of each oil palm were classified into 3 categories of high, moderate and low, each (Table 1). The classification is based on an approximate $1 / 2$ standard deviation of the average $\mathrm{ffb}$ yield of oil palms on the trial site and the acceptable stability of ffb yields obtained in various uniformity studies as presented earlier. Results indicated that about $99 \%$ of the $\mathrm{N}$ treated palms had yields above $30 \mathrm{t} \mathrm{ha}^{-1} \mathrm{yr}^{-1}$ whereas only $22 \%$ achieved similar yield in the control palms. The latter was despite the withdrawal of $\mathrm{N}$ fertilizer for 8 years which suggested that the soil $\mathrm{N}$ status and conditions in part of the field were still favourable for high productivity. The control palms also showed a wider spread in the yield classes with the majority falling into the moderate yield category of between 20 and $30 \mathrm{tha}^{-1} \mathrm{yr}^{-1}$.

In terms of temporal stability of ffb yields, the $\mathrm{N}$ treated palms were mainly classified under the stable to fairly stable categories while the converse was true for the control palms (Table 1). About $50 \%$ of the palms in the control plots had unstable ffb yields indicating large fluctuations which might be due to changing endogenous (physiological yield cycle) and exogenous (environmental) factors ${ }^{[12]}$ The results also showed that application of $\mathrm{N}$ tended to sustain high $\mathrm{ffb}$ yields and improve temporal stability of ffb yields; both highly favourable to the management of oil palm (8). However, no spatial information was obtained from the yield distribution classes as shown in the Table 1 and spatial analysis is required to ascertain them.

The yield class for each palm was used to produce the yield class map by kriging in order to illustrate its distribution as influenced by $\mathrm{N}$ applications (Fig. 3). As expected, the results for $\mathrm{N}$ treated palms showed a uniform distribution of high yield over the trial site. However, in the area without $\mathrm{N}$ application, low yield was observed in the northern part, stretching from east to west. Although it is tempting to separate the two areas for site-specific management, the stability of the ffb yields should be considered also to avoid pitfalls in the interpretation of the yield maps.

The temporal stability maps for both treatments produced by point kriging are presented in Fig. 4. These maps show the ffb yield fluctuations of oil palms with time irrespective of their productivity. Without $\mathrm{N}$ fertilizer application, there was a gradual change in the stability of ffb yields from the western to the eastern part of the field. The western portion of the field had unstable $\mathrm{ffb}$ yields compared with the eastern portion, suggesting that the interpretation of the yield map there would have high uncertainty. Fig. 4 also shows that a portion of the $\mathrm{N}$ treated palms in the north had stable ffb yields while the balance showed fair temporal stability. This implies that fertilizer application, which is an exogenous factor, could not overcome the temporal yield fluctuations of oil palms.

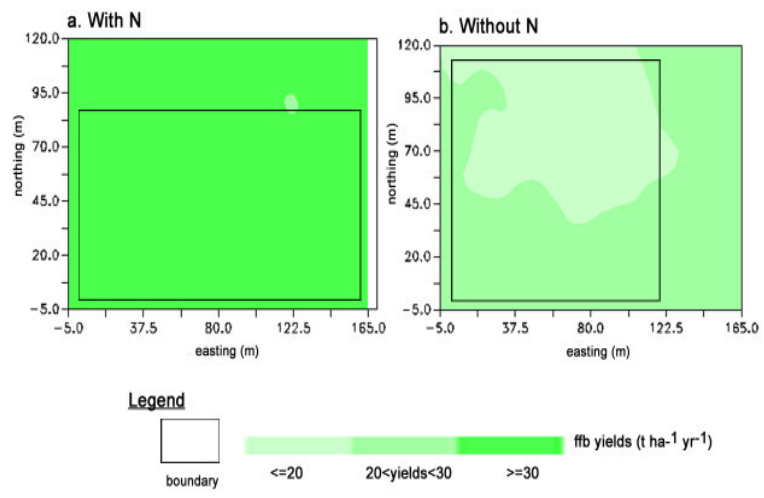

Fig. 3: Spatial trend maps of ffb yields of oil palm in areas with $\mathrm{N}$ (a) and without $\mathrm{N}$ (b) applications 


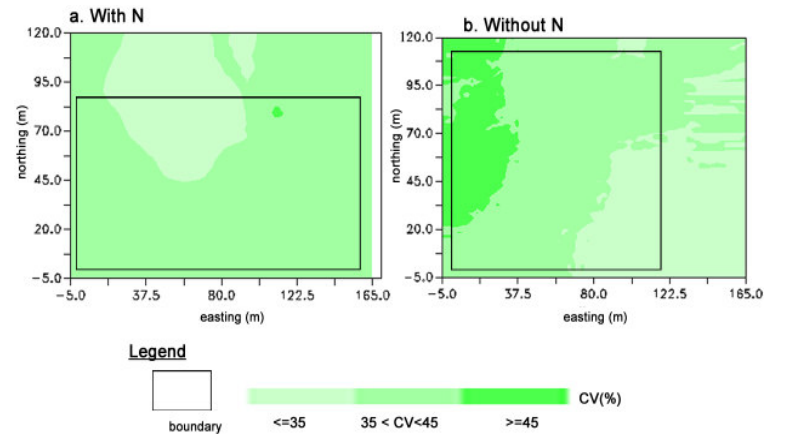

Fig. 4: Temporal yield stability maps of oil palm in areas with $\mathrm{N}$ (a) and without $\mathrm{N}$ (b) applications

Table 2: Management classes based on the combined information of mean and temporal yield stability classes

\begin{tabular}{llll}
\hline $\begin{array}{l}\text { Management } \\
\text { class }\end{array}$ & $\begin{array}{l}\mathrm{ffb} \text { yields } \\
\left(\mathrm{t} \mathrm{ha}^{-1} \mathrm{yr}^{-1}\right)\end{array}$ & $\mathrm{CV}(\%)$ & Remark \\
\hline 1 & $\mathrm{y} \geq 30$ & $\mathrm{CV} \leq 35$ & High, stable yield \\
2 & $20<\mathrm{y}<30$ & $\mathrm{CV} \leq 35$ & Moderate, stable yield \\
3 & $\mathrm{y} \leq 20$ & $\mathrm{CV} \leq 35$ & Low, stable yield \\
4 & $\mathrm{y} \geq 30$ & $35<\mathrm{CV}<45$ & High, fairly stable yield \\
5 & $20<\mathrm{y}<30$ & $35<\mathrm{CV}<45$ & Moderate, fairly stable yield \\
6 & $\mathrm{y} \leq 20$ & $35<\mathrm{CV}<45$ & Low, fairly stable yield \\
7 & $\mathrm{y} \geq 30$ & $\mathrm{CV} \geq 45$ & High, unstable yield \\
8 & $20<\mathrm{y}<30$ & $\mathrm{CV} \geq 45$ & Moderate, unstable yield \\
9 & $\mathrm{y} \leq 20$ & $\mathrm{CV} \geq 45$ & Low, unstable yield \\
\hline
\end{tabular}

Classified management zone maps: The 3 classes each of ffb yield and temporal stability were combined to produce 9 management zones (Table 2). Zone 1 represents the highly desirable oil palms of high, stable yields while the worst scenario is Zone 9 with low, unstable ffb yields. Therefore, the management zones combined the important spatial and temporal features in the $\mathrm{ffb}$ yield variation for decision making. Based on this information, the management zone maps for both treatments were produced using point kriging (Fig. 5).

In the area with $\mathrm{N}$ fertilizer, a zone of high, stable yields was found in the northern portion with lower ffb yields as it radiated southward. It then changed to Zone 4 with high, fairly stable yields. In unfertilized area, there were more management zones with a moderate, stable yield zone in the eastern corner. As it moved towards the northwestern direction, pockets of low, unstable yields were found.

For practical management purposes, it is probably difficult to provide site-specific inputs to the scattered, small areas or strips of different management zones particularly in the unfertilized field (Fig. 5). However, there is a possibility to re-group some of the management zones depending on the management resources $^{[13]}$. For example, the fertilized area could be simply divided into 2 management zones of high, stable

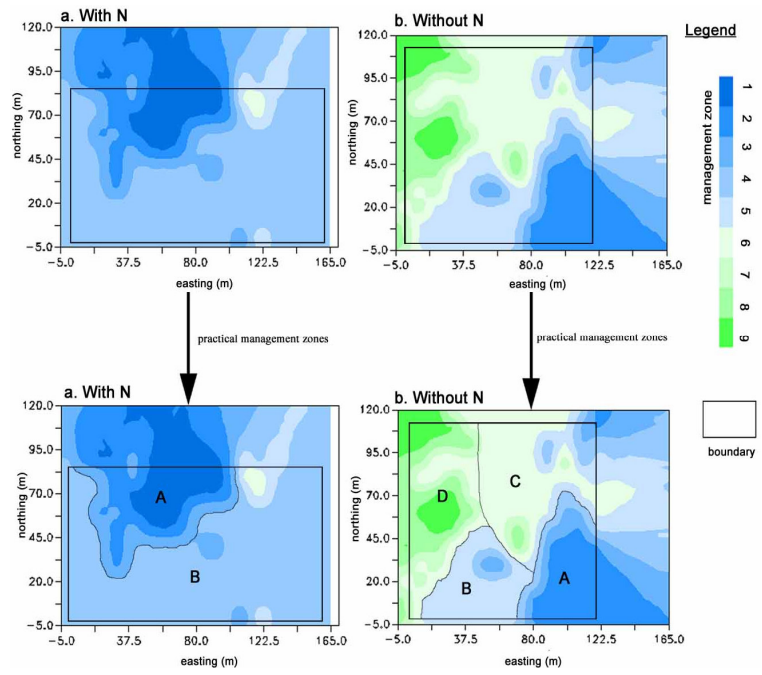

Fig. 5: Practical management zones (2 and 4) in areas with $\mathrm{N}$ (a) and without $\mathrm{N}$ (b) applications based on classified management maps (top two)

yields and high, fairly stable yields (Fig. 5). Similarly, the unfertilized area could be demarcated into 4 management zones of moderate, stable yields (Zone A), moderate, fairly stable yields (Zone B), moderate, unstable yields (Zone C) and low, unstable yields (Zone D). Different strategies could then be formulated to best manage the oil palms in each zone.

\section{CONCLUSIONS}

Removal of $\mathrm{N}$ fertilizer resulted in a significant drop in ffb yields after 1992. High ffb yields above $30 \mathrm{t}$ $\mathrm{ha}^{-1} \mathrm{yr}^{-1}$ with better temporal stability could be obtained with $\mathrm{N}$ applications to the palms. Long-term monitoring of $\mathrm{ffb}$ yields is needed to transform their spatial and temporal pattern for the development of management zones for practical site-specific inputs. However, further work is required to ascertain the optimum spatial and temporal scales of $\mathrm{ffb}$ yields for reliable interpretation of yield maps.

\section{REFERENCES}

1. Goh, K.H. and A. Alwi, 1988. Uniformity Trials with Oil Palms in Malaysia. In: Proceedings of 1987 International Oil Palm/Palm Oil Conference: Progress and Prospects (Halim, A.H., P.S. Chew, B.J. Wood and E. Puspharajah, Eds.). Palm Oil Research Institute of Malaysia and International Society of Planters, Kuala Lumpur, pp: 677-684. 
2. Soh, A.C., C.H. Lee, Y.Y. Yong, C.W. Chin, Y.P. Tan, N. Rajanaidu and P.K. Phuah, 1989. The Precision of Oil Palm Breeding Experiments in Malaysia. In: Applications of Statistics to Perennial Tree Crops (Soh, A.C., N. Rajanaidu and M.H.B. Nasir, Eds.). Palm Oil Research Institute of Malaysia, Kuala Lumpur, pp: 41-50.

3. Goh, K.J., B.H. Tee, A.R. Anuar and C.Y. Woo, 2000. Spatial yield variation of oil palm in a fertiliser response trial in Malaysia. Proceedings of the Soil Science Conference of Malaysia 2000.

4. Emmott, A., J. Hall and R. Matthews, 1997. The potential for precision farming in plantation agriculture. In: Precision Agriculture 97, Vol. 1: Spatial Variability in Soil and Crop. BIOS Scientific Publishers, United Kingdom, pp: 289296.

5. Blackmore, B.S. and G. Larscheid, 1997. Strategies for Managing Variability. In: Precision Agriculture '97, Vol. 2 Technology, IT and Management (Stafford, J.V., Ed.). BIOS Scientific Publishers, United Kingdom, pp: 851-859.

6. Jaynes, D.B. and T.S. Colvin, 1997. Spatiotemporal Variability of Corn and Soybean Yield. Agron. J., 89: 30-37.

7. Goh, K.J., B.H. Tee and A.R. Anuar, 2000. Applicability of Precision Farming for Oil Palm Plantations in Malaysia. In: Seminar on Precision Farming 2000, Universiti Putra Malaysia and Agricultural Inst. of Malaysia, Serdang Malaysia.

8. Chew, J.S. and A.R. Anuar, 2000. Practical Mapping of Oil Palm Yield Using GPS and GIS technologies. In: International Planters Conference on Plantation Tree Crops in the New Millennium: The Way Ahead (Puspharajah, E., Ed.). International Society of Planters, Kuala Lumpur, pp: 793-806.
9. Blackmore, B.S., 2000. The Interpretation of Trends from Multiple Yield Maps. Computers and Electronics in Agriculture, 26 (200): 37-51.

10. Makridakis, S., S.C. Wheelwright and R.J. Hyndman, 1998. Forecasting: Methods and Applications. 3rd Edn. John Wiley and Sons, Inc., New York, pp: 641.

11. McBratney, A.B., B.M. Whelan, J.A. Taylor and M.J. Pringle, 2000. A management opportunity index for precision agriculture. In: Proceedings of the 5th International Conference on Precision Agriculture and other Resource Management (Robert, P.C., R.H. Rust and W.E. Larson, Eds.). Radisson Hotel South, Bloomington, Minnesota, pp: 16-19.

12. Burgess, T.M. and R. Webster, 1980. Optimal Interpolation and Isarithmic Mapping of Soil Properties. I. The semi-variogram and punctual kriging. J. Soil Sci., 31: 315-331.

13. Corley, R.H.V., 1977. Oil Palm Yield Components and Yield Cycles. In: International Developments in Oil Palm (Earp, D.A. and W. Newall, Eds.). International Society of Planters, Kuala Lumpur, pp: $1-15$.

14. McBratney, A.B. and J.A. Taylor, 2000. PV or not PV? In: Proceedings. of the 5th Int. Symposium on Cool Climate Viticulture and Oenology-a Workshop on Precision Management. Melbourne, Australia, Pp: 10. 